\title{
Evaluating Heavy Metals Contamination in Campus Dust in Wuhan, the University Cluster in Central China: Distribution and Potential Human Health Risk Analysis
}

Shan Liu

Hubei Polytechnic University

Xihao Zhang

Wuhan University of Science and Technology

Changlin Zhan

Hubei Polytechnic University

Jiaquan Zhang ( $\nabla$ zhangjiaquan@hbpu.edu.cn )

Hubei Polytechnic University

Jun Xu

Hubei Polytechnic University

Anglv Wang

Hubei Polytechnic University

Huidi Zhang

Hubei Polytechnic University

Jiangyan Xu

Huangshi Ecological Environmental Monitoring Center

Jianlin Guo

Hubei Polytechnic University

Xianli Liu

Hubei Polytechnic University

Xinli Xing

China University of Geosciences

Junji Cao

Institute of Atmospheric Physics Chinese Academy of Sciences

Yulun Xiao

Wuhan University of Science and Technology 
Keywords: Heavy metals, Campus dust, Risk assessment, Spatial distribution, Students and teachers Posted Date: July 30th, 2021

DOI: https://doi.org/10.21203/rs.3.rs-512143/v1

License: (c) (1) This work is licensed under a Creative Commons Attribution 4.0 International License. Read Full License

Version of Record: A version of this preprint was published at Environmental Earth Sciences on March 25th, 2022. See the published version at https://doi.org/10.1007/s12665-022-10321-z. 

Zhang ${ }^{1,2}$, Jiangyan $\mathrm{Xu}^{4}$, Jianlin Guo ${ }^{1,2}$, Xianli Liu ${ }^{1,2}$, Xinli Xing ${ }^{5}$, Junji Cao ${ }^{6}$, Yulun Xiao ${ }^{3}$ 
Abstract: The potential health risk of heavy metals (HMs) in campus dust may threaten the health of thousands of students, teachers, and their families in Wuhan, the university cluster in Central China every day. In this research, the pollution characteristics and health risk with HMs was the first time presented in campus dust from the canteen, playground, dormitory, and school gate to date. The average HMs concentration in campus dusts ranked $\mathrm{Pb}(83.5 \mathrm{mg} \mathrm{kg}-1)>\mathrm{Cu}(70.2 \mathrm{mg} \mathrm{kg}-1)>\mathrm{Zn}$ $(47.2 \mathrm{mg} \mathrm{kg}-1)>\mathrm{Cr}(46.0 \mathrm{mg} \mathrm{kg}-1)>\mathrm{Ni}(22.7 \mathrm{mg} \mathrm{kg}-1)>\mathrm{As}(15.2 \mathrm{mg} \mathrm{kg}-1)>\mathrm{Cd}(3.38 \mathrm{mg} \mathrm{kg}-1)$. The HMs would more likely to accumulate in dormitory dust and canteen dust. In the downtown area, $\mathrm{Zn}$, As, and $\mathrm{Cd}$ had been preliminarily identified from fossil fuel combustion and natural geochemical processes. $\mathrm{Cu}$ and $\mathrm{Pb}$ would source from cooking and traffic transportation. $\mathrm{Ni}$ and $\mathrm{Cr}$ would likely reflect the contributions of natural soil weathering. Although, no significant non-carcinogenic health risks were found to students or teachers from campus dust. Their children would more likely to exposure health risks when eating in the canteen, playing on the playground, or walking around the school gate. While the incremental lifetime cancer risk values revealed respiratory intake of HMs does not pose a carcinogenic risk on the campus.

Keywords: Heavy metals; Campus dust; Risk assessment; Spatial distribution; Students and teachers

\section{Introduction}

Heavy metals (HMs) are ubiquitous in the environment. They originate from both natural and anthropogenic activities (Wei and Yang, 2010). Based on recent studies, HMs would have strong capacities to migrate, enrich, and contaminate (Rahman et al., 2019). Additionally, HMs are usually non-degradable and there is no known homeostasis mechanism for them (Doabi et al, 2018). People would be exposed to them via multi-pathway exposure (Sun et al., 2019). HMs in particulates, such as chromium $(\mathrm{Cr})$, Zinc $(\mathrm{Zn})$, copper $(\mathrm{Cu})$, lead $(\mathrm{Pb})$, nickel $(\mathrm{Ni})$, cadmium $(\mathrm{Cd})$, and arsenic $(\mathrm{As})$, have 
already been proved to lead to significant threats to ecosystems and cause carcinogenic and non-carcinogenic risk for people (Doabi et al., 2018; Men et al., 2018; Sahakyan et al., 2019). Additionally, as the source and sink for HMs, surface dust has become a hot topic in environmental pollution research, especially for urban atmospheric particulate (Men et al., 2018). Among all the assessment methods, the geo-accumulation index has been widely in HMs pollution assessment due to its comprehensive consideration of anthropogenic influences as well as natural sources for environmental input (Qadeer et al., 2020;). Moreover, health risk models origination at the U.S. Environmental Protection Agency (USEPA), have also been widely used to evaluate the health risk of HMs pollutants in urban dust, such as Kermanshah (Doabi et al., 2018), Beijing (Wei et al., 2015), and Dhaka (Rahman et al., 2019). Indicating, the infrastructural development in urban areas has placed great stress on the local environment (Soltani et al., 2015).

Even though lots of studies about HMs health assessment had been done in modernize cities (Doabi et al., 2018), the information about the health assessment to a particular group in a specific living environment, such as the education area, was still limited. Only a few pieces of research had a focus on HMs pollution in the education area. For example, based on the pollution characteristics and spatial distribution of HMs from nursery and primary school dust in Xi'an, Chen et al. (2014) had revealed the hot-spot area of HMs area mainly associated with industrial activities and traffic density, and limited adverse non-cancer health risk to children due to dust exposure. Li et al. (2017) had compared the pollution characteristics and risk assessment of HMs from street dust in different functional areas in Chengdu. Revealing, the concentration of HMs in the education area was relatively lower than in commercial area, traffic area, residential area, and park area. 
families (Li et al., 2017; Wei et al., 2015). They study, work, and live on campus every day. With relatively large-scale campuses, universities or colleges can be always considered relatively isolated communities (Li et al., 2017). Especially in Wuhan, one of the four biggest capitals of education in China, with 84 colleges and universities including over 150,000 graduate students and 1 million undergraduate students by the end of 2019. The lack of studies would limit our understanding of the contributions of spatial distribution characteristics, pollution, and potential human health risks to HMs in dust from different functional areas on campus, such as dormitory, canteen, playground, and school gate. Indicating, thousands of students, teachers, and their families may expose to the danger of HMs when they are studying, eating, playing, and resting every day, and we never evaluate the potential health risk at these places.

To fill the knowledge gap discussed above, in the present research, our study were (1) to determine the current status of $\mathrm{HMs}$ (including $\mathrm{Cu}, \mathrm{Pb}, \mathrm{Zn}, \mathrm{Cd}, \mathrm{Ni}, \mathrm{As}, \mathrm{Cr}$ ) in dust from different universities and colleges in Wuhan; (2) to analyze the spatial distribution of these HMs in dust from four different functional areas (including the playground, dormitory, canteen, and school gate) in universities and colleges; (3) to evaluate the pollution of these HMs in campus dust using the Geo-accumulation Index; and (4) to assess the carcinogenic and non-carcinogenic health risks associated with these HMs.

\section{Materials and methods}

\subsection{Study area}

Wuhan is the capital of Hubei province in Central China (Fig. 1), with a total resident population of over 10 million. With a total of eighty-four universities and colleges, Wuhan is the university cluster in Central China. Most of the colleges and universities are located on the east side of the Yangtze River, which is the educational and resident area in Wuhan. Moreover, Wuhan is also the biggest 
developing city in Central China. The GDP of Wuhan had reached 1.62 trillion yuan by the end of 2019. The climate of the area is humid subtropical with an average annual temperature of $15.8-17.5^{\circ} \mathrm{C}$ and an annual rainfall of $1269 \mathrm{~mm}$. Based on the meteorological statistics of the Hubei meteorological service since 1990, the local dominant wind direction is northeaster in winter (Liu et al., 2020b).

\subsection{Sampling and preparation}

From November $5^{\text {th }}$ to $9^{\text {th }}, 2019$, a total of seventy samples were collected from fourteen universities and colleges in two parallel zones (Fig. 1). Zone A is the downtown area with heavy traffic and intensive residence, while Zone B is the economic development area with lots of construction projects and industrial parks (Fig. 1).

The sampling universities and colleges are including famous universities, such as Wuhan University (WH-U), Huazhong University of Science and Technology (HZ-U), and Wuhan University of Technology (WT-U). The campus area of them were $3.47 \mathrm{~km}^{2}, 4.67 \mathrm{~km}^{2}$, and $2.664 .67 \mathrm{~km}^{2}$, respectively (Fig. 1). These kinds of universities are almost small independent communities. However, some local universities would have a relatively small campus. The campus area of Wuhan University of Science and Technology (ST-U), Hubei University (HB-U), Zhongnan University of Economics and Law (ZE-U), Hubei University Of Technology (HT-U), China University Of Geosciences (CG-U), Wuhan Textile University (WHT-U), Hubei University Of Education (HE-U), City College, Wuhan University of Science and Technology (CC-C), Hubei University of Traditional Chinese Medicine (CM-U) and Wuchang University of Technology (WT-U) was $1.70 \mathrm{~km}^{2}, 1.4 \mathrm{~km}^{2}, 1.87 \mathrm{~km}^{2}, 1.11 \mathrm{~km}^{2}$, $1.43 \mathrm{~km}^{2}, 1.33 \mathrm{~km}^{2}, 1.14 \mathrm{~km}^{2}, 0.57 \mathrm{~km}^{2}, 0.79 \mathrm{~km}^{2}$, and $0.82 \mathrm{~km}^{2}$, respectively (Fig. 1). These kinds of universities would have a relatively tight link to local development. Moreover, the ZE-U was divided into Shouyi Campus (ZE-SC) and Nanhu Campus (ZE-NC), which are located in different areas (Fig. 
107 Moreover, ST-U located in the north of Zone A. HB-U, WH-U, ZE-SC, WT-U, and HT-U located

108 in the center of Zone A. CM-U located in the southwest of Zone A. While, CC-C located in the

109 northeast of Zone B. HZ-U, CG-U, WHT-U, HE-U and ZE-NC located in the center of the Zone B.

110 WCT-U located in the south of Zone B (Fig. 1). Additionally, four different functional areas in each

111 campus were chosen to collect dust samples, including playground dust, dormitory dust, canteen dust,

112 and school gate dust. Details of the sampling sites are provided in Table S1. 


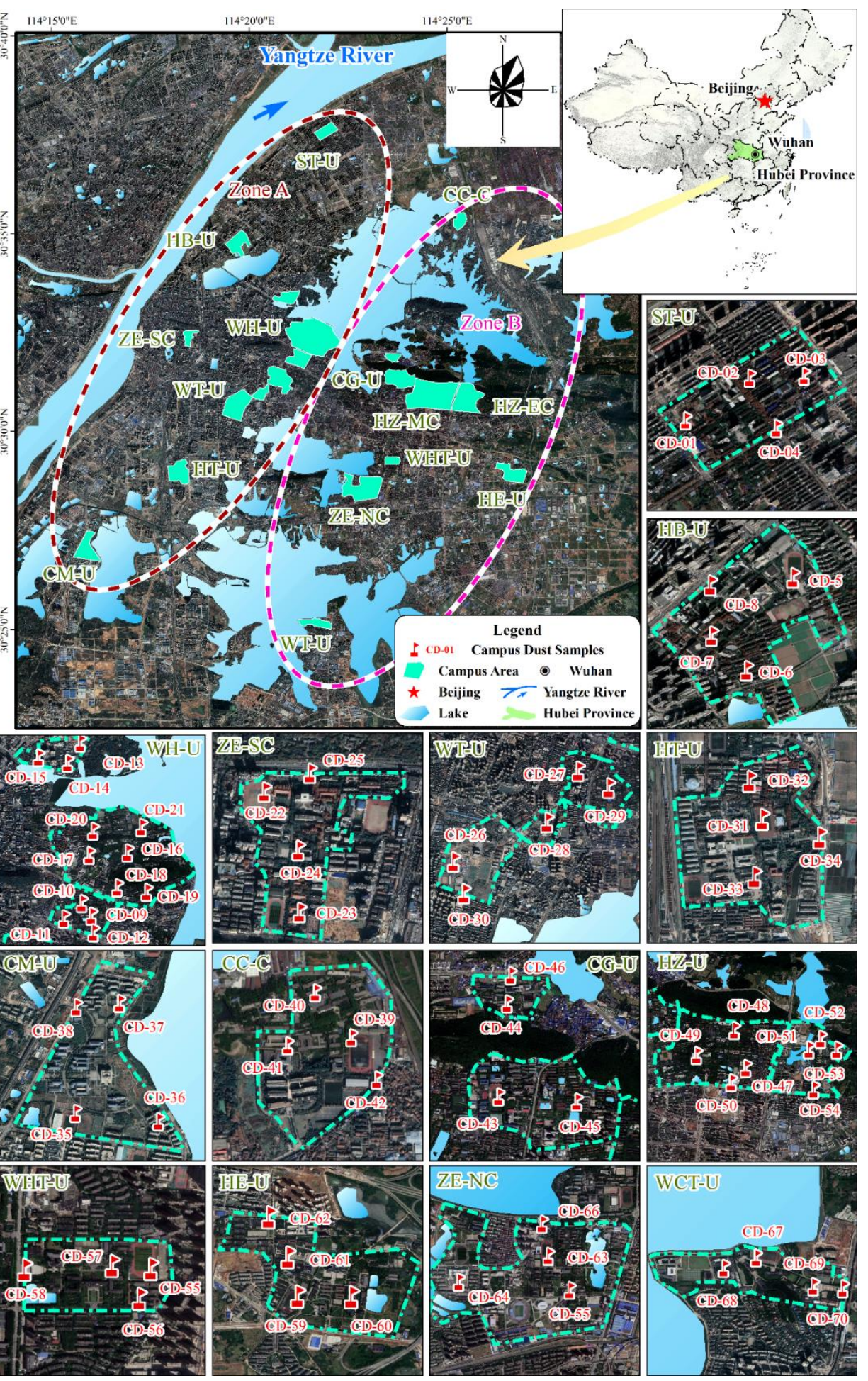

114 Fig. 1. General map showing location of study area and sampling sites at universities and colleges in Wuhan.

116 During sampling, approximately $100 \mathrm{~g}$ of the dust particles were collected using plastic brushes

117 and dustpans by a gentle sweeping motion from buildings at a height of $1.5-2 \mathrm{~m}$. After each sampling, 
brushes, and dustpans were cleaned with paper towels. All samples were stored in paper bags wrapped with solvent-rinsed aluminum foil and then sealed in polyethylene bags for transport to the laboratory. The samples were then placed in a desiccator to get rid of moisture, and then a $100 \mu \mathrm{m}$ sieve was used to remove coarse debris and small stones. And an agate mortar was used to grind and homogenize. Then all the samples had been sieved to $63 \mu \mathrm{m}$. Eventually, after homogenization, samples were placed in an air-tight container for storage.

\subsection{Chemical analyses}

Seven kinds of heavy metals $(\mathrm{Cu}, \mathrm{Pb}, \mathrm{Zn}, \mathrm{Cd}, \mathrm{Ni}, \mathrm{As}$, and $\mathrm{Cr})$ in all dust had been determined in this research. They were analyzed according to the procedure explained by Cui et al. (2020). Briefly, the sieved samples $(0.2 \mathrm{~g})$ were weighed and placed into a digestion vessel with $\mathrm{HNO}_{3}, \mathrm{HCl}$, and $\mathrm{HF}$. The vessel was sealed tightly and placed in a digestion chamber. After cooling, the samples were collected, filtered, and diluted to a constant volume. To prevent contamination of the samples, all-glass dished and digestion vessels were immersed in $5 \%$ nitric acid for $24 \mathrm{~h}$, then washed and dried before use. The concentrations of As were measured using an AFS-203E atomic fluorescence spectrophotometer. The concentrations of $\mathrm{Cu}, \mathrm{Pb}, \mathrm{Zn}, \mathrm{Cd}, \mathrm{Ni}$, and $\mathrm{Cr}$ were measured with an inductively coupled plasma source-mass spectrometer (Perkin - Elmer Elan 9000).

The purity of all reagents was an excellent level of pure. The accuracy and precision of analysis were established by analysis of the national one-level soil standard materials. These tests showed that the analytical results were accurate and reliable. The logarithmic deviation $(\Delta \lg [\mathrm{C}])$ for all heavy metals was smaller than 0.05 , and the quoted rate was $100 \%$. Procedural blanks, spiked blanks, sample duplicates $(10 \%)$ were analyzed to evaluate the precision. The relative double difference (RD) 
is $<10 \%$ and the analysis yield was up to $100 \%$. The heavy metals found in the procedural blanks were generally below the limit of detection. No target heavy metals were detected in blanks. All the test results conform to monitoring requirements.

\subsection{Heavy metals contamination assessment}

The geo-accumulation index $\left(\mathrm{I}_{\text {geo }}\right)$ was used to estimate the natural variation in the heavy metal distribution in soil and identify the effects of human activities on the environment by Muller (1969) by using the following equation.

$I_{\text {geo }}=\log _{2}\left(\frac{C_{n}}{1.5 \times B_{n}}\right)$

where $C_{n}$ is the concentration of heavy metal in the surface dust and $B_{n}$ is the geochemical background concentration value of corresponding measured heavy metals in Hubei province, China. Factor 1.5 is considered to be a background matrix correction value to accommodate some human effects and to allow possible fluctuations and variations in the reference background values (Kusin et al., 2018). The $\mathrm{I}_{\text {geo }}$ is evaluated by dividing it into seven classes as given in Table S2.

\subsection{Source apportionment method}

To evaluate the obtained results, principal component analysis (PCA) was used. It was widely used to extract a smaller number of independent factors among available data for analyzing variables relationships (Liu et al., 2020a). PCA could make it easier to interpret a given multidimensional system by displaying the correlations among the original variables (Zhao et al., 2020). Additionally, PCA has also widely applied to various environmental media, to identify pollution sources and to apportion natural versus anthropogenic contributions (Bi et al., 2020). The components of the PCA were transformed using varimax rotation with Kaiser Normalization after the analysis (Kaiser, 1960). 
In the current study, PCA was used to elucidate the latent relationships between variables and for investigating pollutant sources. The statistical analyses were performed using SPSS package version 22.0.

\subsection{Health risk assessment}

Nowadays, health risk assessment has been used to quantitatively describe the possibility of carcinogenic and non-carcinogenic risks of heavy metal pollutants to human beings, thus human health with linking environmental pollution. Basing on behavioral and physiological differences, people could be divided into adults and children (Liu et al., 2019). In Chain, most of the undergraduate and graduate students are over 18 years old. Indicating, they have already been adults. Therefore, in our research, adults mainly refer to students and teachers. Moreover, surface dust mainly enters the human body through skin contact, respiration, and hand-mouth direct intake (USEPA, 2009). The average daily dose (ADD) was calculated for the three exposure pathway: ingestion, inhalation, and dermal absorption using the following formulas (USEPA, 2009; Zhang et al., 2019)

$A D D_{\text {ing }}=\frac{C \times I n g R \times E F \times E D \times C F}{B W \times A T}$

$A D D_{i n h}=\frac{C \times E F \times E D \times I n h R}{B W \times A T \times P E F}$

$A D D_{\text {derm }}=\frac{C \times E F \times E D \times S L \times S A \times A B S \times C F}{B W \times A T}$

where $\mathrm{ADD}_{\text {ing }}$ is the average daily exposure to particulates in dust through the hand-mouth intake in $\mathrm{mg}(\mathrm{kg} \mathrm{d})^{-1}, \mathrm{ADD}_{\text {inh }}$ is the average daily exposure to particulates in dust through respiration pathways in $(\mathrm{kg} \mathrm{d})^{-1}, \mathrm{ADD}_{\text {derm }}$ is the average daily exposure to particulates in dust through skin contact in $(\mathrm{kg} \mathrm{d})^{-1}$. The other parameters are defined, and values are provided in Table S3. Parameters were taken from the USEPA evaluation standards and corrected for local factors in China. 

the human population (Gao et al. 2015), HQ is the ratio of the average daily dose to the RfD of a specific metal for a single pathway, HI is a cumulative metric for HQs for individual heavy metals and exposure pathways. Base on USEPA (2001) report, if $\mathrm{HI}<1$, it is unlikely to hurt the health of the exposed individual. However, if $\mathrm{HI}>1$, it indicates that heavy metals would cause non-carcinogenic risk to the population (Eziz et al. 2018). incremental lifetime cancer risk (ILCR) was estimated as the incremental probability of an individual developing cancer over time due to exposure to carcinogenic heavy metals(USEPA, 1989). The ILCR was determined as in the following formula (Doabi et al., 2018; Zhang et al., 2019): $1 \times 10^{-6}$ it is accepted that there are no significant health risks for humans. While the acceptable range of ILCR is between $1 \times 10^{-6}-1 \times 10^{-4}$ (Liu et al. 2019). According to the previous researches, RfD and 


\subsection{Data analysis}

The minimum, maximum, median, mean, standard deviation (SD), and coefficient of variations

(CV) of research data were calculated with SPSS 22.0 statistical package (Statistical Product and

Service Solutions, SPSS Inc., USA). The standard deviation and coefficient of variations were

Two data mapping software packages were used including ArcGIS desktop 10.5 (ESRI, Redlands, CA,

USA) and OriginPro 2018C (OriginLab, Northampton, Massachusetts, USA).

\section{Results and discussion}

\subsection{Heavy metal concentration in campus dust}

$\left.\mathrm{kg}^{-1}\right)>\mathrm{Cu}\left(70.2 \pm 52.2 \mathrm{mg} \mathrm{kg}^{-1}\right)>\mathrm{Zn}\left(47.2 \pm 102 \mathrm{mg} \mathrm{kg}^{-1}\right)>\mathrm{Cr}\left(46.0 \pm 27.8 \mathrm{mg} \mathrm{kg}^{-1}\right)>\mathrm{Ni}(22.7 \pm$ 
higher than their corresponding background values, respectively. These results indicated that $\mathrm{Cu}, \mathrm{Pb}$, and $\mathrm{As}$ in most campus dust mainly originated from anthropogenic activities, whereas $\mathrm{Ni}, \mathrm{Zn}$, and $\mathrm{Cr}$ might primarily derive from natural sources (Zhao et al., 2019).

Compared with the reported concentration of HMs in school dust and road dust in the education area of some typical cities in China, the concentrations of $\mathrm{Cu}, \mathrm{Pb}, \mathrm{Ni}$, and $\mathrm{Cr}$ in campus dust from Wuhan was similar to those in road dust in education from Chengdu (Li et al., 2017) and Beijing (Wei et al., 2015) (Table S5). Moreover, the concentrations of $\mathrm{Pb}, \mathrm{Ni}$, and $\mathrm{Cr}$ in campus dust from Wuhan were lower than those in school dust from Xi'an (Chen et al., 2014). Especially, the concentrations of $\mathrm{Zn}$ in Wuhan campus dust were typically lower than those from Chengdu (Li et al., 2017), Beijing (Wei et al., 2015), and Xi'an (Chen et al., 2014) (Table S5). Comparing the concentration of HMs in road dust and urban dust of some typical cities within and outside the country, the concentrations of most HMs in campus dust in Wuhan were lower than those in Turin (Padoan et al., 2017) and Thessaloniki (Bourliva et al., 2017), except for Cd (Table S5). Moreover, the concentration of $\mathrm{Cu}, \mathrm{Pb}$, $\mathrm{Zn}, \mathrm{Ni}, \mathrm{As}$, and $\mathrm{Cr}$ from urban dust and road dust of some big cities in China are much higher than those in our study, such as Beijing (Men et al., 2018), Xi'an (Cao et al., 2011), Shanghai (Bi et al., 2018), Nanjing (Hu et al., 2011), and other 58 cities (Zhang et al., 2019). A big city like Wuhan is an assembly of different land-use types, the distinctive artificial activities in each functional area could release different kinds of heavy metals content (Trujillo-Gonzalez et al., 2016). As universities and colleges always have relatively large campus areas, artificial activities may have less influence on campus areas (Li et al., 2017). Showing the concentration of most HMs in campus dust from Wuhan was lower than that in urban dust or road dust from other cities.

However, only the concentration of Cd in Wuhan was significantly higher than those in other cities 

already supported that $\mathrm{Cd}$ had a relatively higher concentration in Wuhan (Tadesse et al., 2018). As

247 Cd was relatively abundant in the crust rocks of the Yangtze River basin and Hanjiang River basin,

248 the natural factors may be a source for the relatively high level of Cd concentration in Wuhan (Ma et

249 al., 2005; Zhang et al., 2015). Still, fossil fuel combustion and industrial discharges from smelting and

250 electric plating may significantly contribute to the wide spreading of Cd in Wuhan (Wei et al. 2009;

251 Zhang et al., 2015).

252

Table 1 Statistical results of heavy metals in campus dusts (Unit: $\mathbf{~ m ~ k g}^{-1}$ )

\begin{tabular}{cccccccc}
\hline Statistic & $\mathrm{Cu}$ & $\mathrm{Pb}$ & $\mathrm{Zn}$ & $\mathrm{Cd}$ & $\mathrm{Ni}$ & $\mathrm{As}$ & $\mathrm{Cr}$ \\
\hline All $\left(\mathrm{N}^{\mathrm{a}=70}\right)$ & & & & & & & \\
Minmum & 22.4 & 27.1 & 0.386 & 1.87 & 11.3 & 4.37 & 0.260 \\
Maximum & 441 & 314 & 623 & 16.4 & 83.3 & 33.5 & 161 \\
Median & 77.8 & 96.5 & 84.0 & 3.84 & 27.1 & 15.5 & 49.9 \\
Mean & 70.2 & 83.5 & 47.2 & 3.38 & 22.7 & 15.2 & 46.0 \\
SD & 52.2 & 57.8 & 102 & 2.25 & 13.2 & 6.20 & 27.8 \\
$\mathrm{CV}^{\mathrm{c}}(\%)$ & $67.0 \%$ & $59.9 \%$ & $122.0 \%$ & $58.5 \%$ & $48.6 \%$ & $39.9 \%$ & $55.7 \%$
\end{tabular}

Zone A $\left(\mathrm{N}^{\mathrm{a}}=38\right)$

\begin{tabular}{cccccccc} 
Minmum & 22.4 & 30.7 & 0.386 & 1.87 & 11.3 & 6.19 & 15.4 \\
Maximum & 218 & 314 & 623 & 6.31 & 83.3 & 33.5 & 119 \\
Median & 77.1 & 96.8 & 107 & 3.38 & 29.8 & 15.6 & 53.9 \\
Mean & 73.7 & 85.6 & 83.2 & 3.22 & 25.8 & 15.6 & 48.9 \\
\hline
\end{tabular}




\begin{tabular}{|c|c|c|c|c|c|c|c|}
\hline $\mathrm{SD}^{\mathrm{b}}$ & 34.0 & 56.0 & 114 & 0.95 & 15.2 & 5.84 & 23.5 \\
\hline $\mathrm{CV}^{\mathrm{c}}(\%)$ & $44.1 \%$ & $57.8 \%$ & $107.0 \%$ & $28.2 \%$ & $51.2 \%$ & $37.5 \%$ & $43.5 \%$ \\
\hline \multicolumn{8}{|l|}{ Zone $\mathrm{B}\left(\mathrm{N}^{\mathrm{a}}=32\right)$} \\
\hline Minmum & 24.4 & 27.1 & 1.06 & 2.23 & 13.2 & 4.37 & 0.26 \\
\hline Maximum & 441 & 308 & 381 & 16.4 & 49.4 & 31.0 & 161 \\
\hline Median & 78.7 & 96.1 & 56.7 & 4.40 & 23.9 & 15.5 & 45.3 \\
\hline Mean & 65.8 & 81.8 & 31.3 & 3.58 & 21.3 & 13.9 & 42.0 \\
\hline $\mathrm{SD}^{\mathrm{b}}$ & 67.7 & 59.8 & 77.8 & 3.07 & 9.12 & 6.60 & 31.6 \\
\hline $\mathrm{CV}^{\mathrm{c}}(\%)$ & $86.0 \%$ & $62.3 \%$ & $137 \%$ & $69.9 \%$ & $38.2 \%$ & $42.6 \%$ & $69.9 \%$ \\
\hline Reference values ${ }^{\mathrm{d}}$ & 30.7 & 26.7 & 83.6 & 0.172 & 37.3 & 12.3 & 86.0 \\
\hline
\end{tabular}

$254 \quad \mathrm{~N}^{\mathrm{a}}$ indicates samples number.

$255 \quad \mathrm{SD}^{\mathrm{b}}$ indicates standard deviation.

$256 \mathrm{CV}^{\mathrm{c}}$ indicates coefficient of variation.

257 Reference values ${ }^{d}$ indicates local soil background values CNEMC (1990)

$258 \quad 3.2$ Spatial distribution of heavy metal pollution in campus dust

259 3.2.1. Spatial distribution of heavy metal pollution

260 The mean values of $\mathrm{I}_{\text {geo }}$ for $\mathrm{Cu}, \mathrm{Pb}, \mathrm{Zn}, \mathrm{Cd}, \mathrm{Ni}, \mathrm{As}$, and $\mathrm{Cr}$ in dust samples of universities and

261 colleges were shown in Fig. 2. The contamination level of Cd was the highest of the seven HMs,

262 followed by $\mathrm{Pb}$ and $\mathrm{Cu}$. According to the standard of contamination degree by $\mathrm{I}_{\text {geo }}$ (Förstner et al.,

263 1990), the mean values of $I_{\text {geo }}$ indicated heavily contaminated with campus dust by Cd, slightly to

264 moderately contaminated by $\mathrm{Cu}$ and $\mathrm{Pb}$, uncontaminated to slightly contaminated by $\mathrm{As}$ and $\mathrm{Zn}$,

uncontaminated by $\mathrm{Ni}$ and $\mathrm{Cr}$. These results also revealed that the education areas were relatively low 


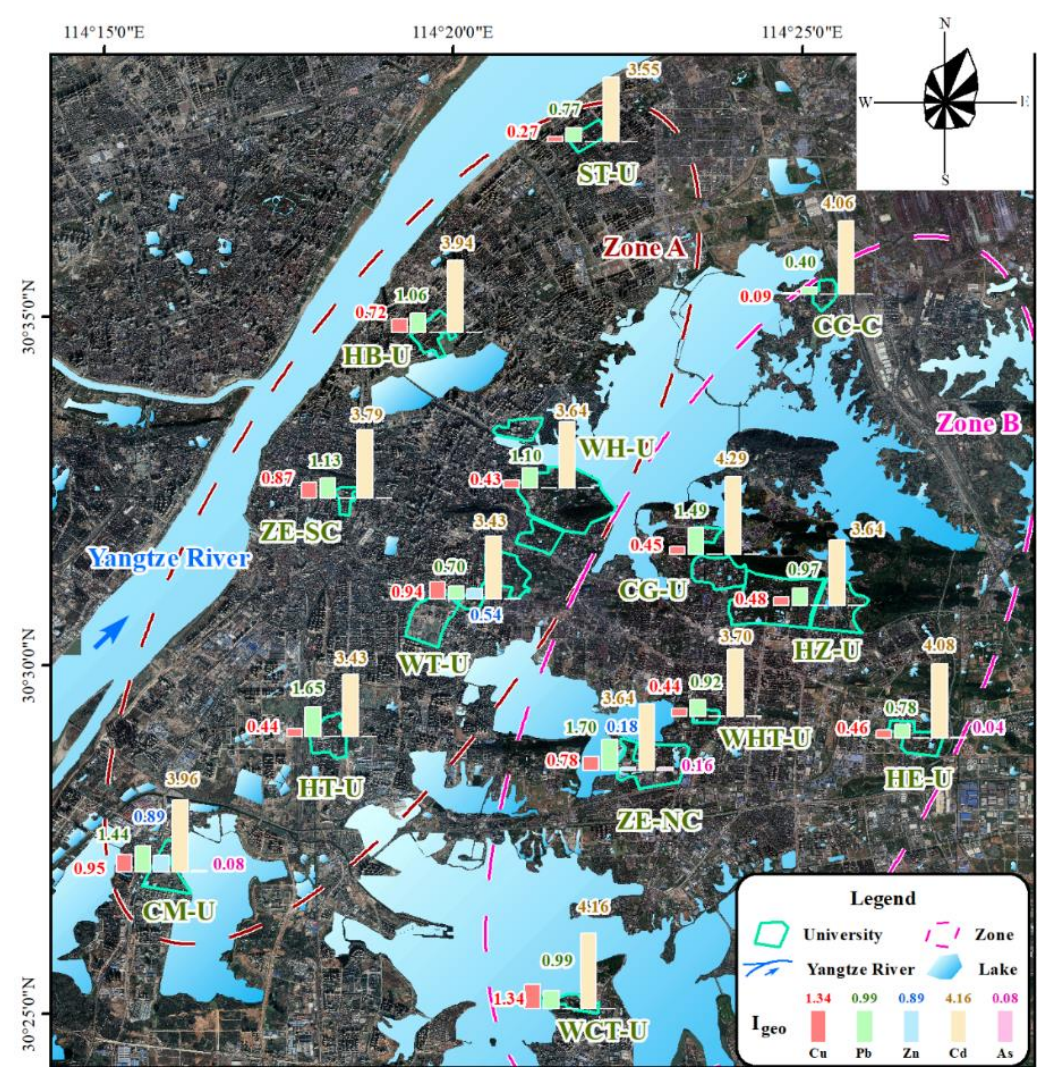
was not shown on the figure. from the seven universities were ranked as follows: ST-U (northeast of Zone A) $<$ HB-U, ZE-SC, 
HE-U, and ZE-NC (center of Zone B) < WCT-U (southwest of Zone B), indicating the accumulation of HMs in campus dust would be influenced by local meteorological conditions.

Additionally, comparing the $\mathrm{I}_{\text {geo }}$ values of $\mathrm{Cu}$ and $\mathrm{Pb}$ from different universities in Zone $\mathrm{A}$ and $\mathrm{B}$, the results showed that the $\mathrm{I}_{\mathrm{geo}}$ value of $\mathrm{Cu}$ from the universities in Zone A was relatively higher than that from the universities, which is located in a similar position in Zone B (Fig. 2). Such as, Igeo value of Cu from ST-U (northeast of Zone A) was relatively higher than that from CC-C (northeast of Zone B). $\mathrm{I}_{\text {geo }}$ values of $\mathrm{Cu}$ from HB-U, ZE-SC, WH-U, WT-U, and HT-U (center of Zone A) were relatively higher than that from CG-U, HZ-U, WHT-U, HE-U, and ZE-NC (center of Zone B). And Igeo value of $\mathrm{Cu}$ from $\mathrm{CM}-\mathrm{U}$ (southwest of Zone A) was relatively higher than that from WCT-U (southwest of Zone B). However, the $\mathrm{I}_{\text {geo }}$ values of $\mathrm{Pb}$ from the universities in Zone A and Zone $\mathrm{B}$ showed opposite results. As we know, Zone B is an economic development area with lots of construction projects and industrial parks, $\mathrm{Cu}$ and $\mathrm{Pb}$ may source of traffic emission, industrial emission, and city construction (Dong et al., 2017). Especially, Igeo values of HMs in WCT-U were higher than those in other universities. During sampling, a construction site is located just $100 \mathrm{~m}$ away from the south of WCT-U. It kept construction for one year already (Fig.1). The campus dust in WCT-U would already be affected by local city construction. While Zone A is the downtown area with heavy traffic, $\mathrm{Cu}$ accumulation may commonly release through the wear of vehicular materials, such as brakes (Świetlik et al., 2015). And Pb may also from anthropogenic source, such as the use of leaded gasoline (Doabi et al., 2018). Moreover, the $\mathrm{I}_{\text {geo }}$ values of Pb in Zone A were relatively lower than those in Zone B. These results also revealed that traffic-related exhaust emissions of metals were substantially reduced through the phasing out of leaded gasoline and the implementation of other exhaust pollution controls measures in the downtown area (Tang et al., 2017). 
The results of $\mathrm{Igeo}_{\mathrm{geo}}$ of HMs from different functional areas were presented in Fig. 3 and Table S6.

302 Generally, for most HMs, the Igeo value from different functional areas showed as similar in Fig. 3.

Indicating, the pollution characteristics for most HMs in campus dust were effect by local atmospheric conditions (Liu et al., 2020b). Moreover, the mean values of $\mathrm{I}_{\mathrm{geo}}$ of $\mathrm{As}, \mathrm{Ni}, \mathrm{Zn}$, and $\mathrm{Cr}$ were lower than 0 . Indicating, the campus area in Wuhan had less affected by these metals. All the Igeo values for $\mathrm{Ni}$ and $\mathrm{Cr}$ in playground dust, dormitory dust, and school gate dust were lower than 0 .

Revealing, these areas were not threatened by these metals.

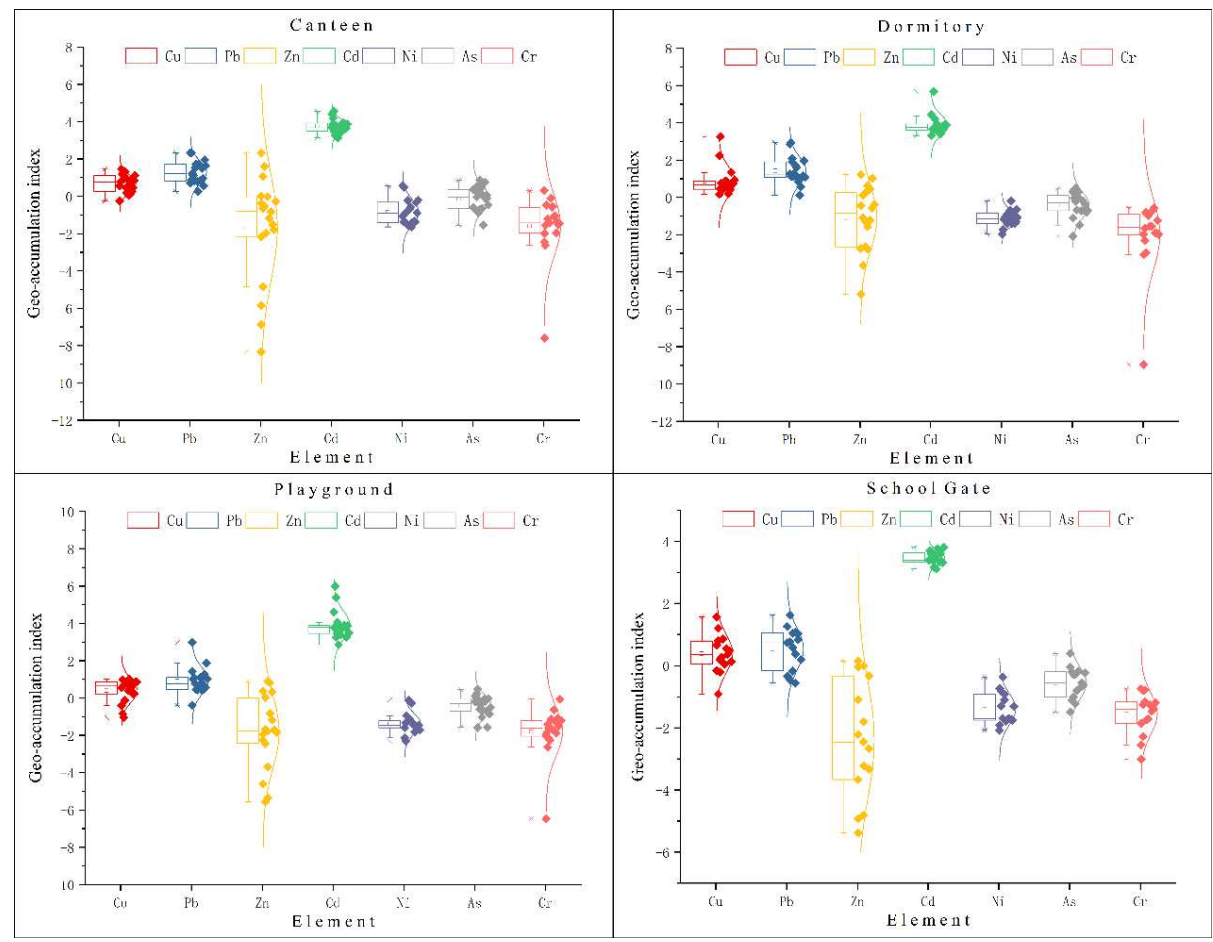

Fig. 3. The statistic of Geo-accumulation index (Igeo) values of HMs in campus dusts around canteen, dormitory, playground, and school gate areas.

Fig. 3 and Table S6 also showed, the playground dust was uncontaminated or slightly contaminated 
Cd were over 2. Indicating, playground dust was heavy to extremely contaminated by $\mathrm{Cd}$. In dormitory dust, the mean $\mathrm{I}_{\mathrm{geo}}$ value for $\mathrm{Pb}(1.43)$ and $\mathrm{Cu}(0.86)$ was almost significantly higher than that in playground dust, respectively. While it was uncontaminated or moderately contaminated by $\mathrm{Zn}$. The mean $\mathrm{I}_{\text {geo }}$ value for $\mathrm{Cd}$ was 3.89 in dormitory dust. Showing, dormitory dust was also heavily to extremely contaminated by $\mathrm{Cd}$. Comparing with dormitory dust and playground dust, the Igeo values for all HMs were relatively lower in school gate dust. Most $\mathrm{Igeo}_{\text {geo }}$ values for As and $\mathrm{Zn}$ were below 0 . The $\mathrm{I}_{\text {geo }}$ values for $\mathrm{Cu}$ in $87 \%$ samples and $\mathrm{Pb}$ in $67 \%$ samples were below 1. Indicating, school gate dust was uncontaminated or moderately contaminated by these metals. Moreover, all the Igeo values for $\mathrm{Cd}$ were between 3 and 4 . Heavily contaminated by $\mathrm{Cd}$ could be revealed in school gate dust. Canteen dust was contaminated by all the HMs in different degrees. The $\mathrm{I}_{\text {geo }}$ value for $\mathrm{Cr}$ in $5 \%$ samples, As in $47 \%$ samples, $\mathrm{Ni}$ in $11 \%$ samples, $\mathrm{Zn}$ in $21 \%$ samples, $\mathrm{Cu}$ in $99 \%$ samples, $\mathrm{Pb}$ in all samples, and $\mathrm{Cd}$ in all samples was over 0 in canteen dust. The $\mathrm{I}_{\text {geo }}$ value for $\mathrm{Zn}$ in $5 \%$ samples and $\mathrm{Pb}$ in $11 \%$ samples was over 2 . Additionally, $16 \%$ of the $\mathrm{I}_{\text {geo }}$ value for $\mathrm{Cd}$ was over 4 and others were over 3. Revealing, the canteen dust was also heavily to extremely contaminated by $\mathrm{Cd}$.

As far as the overall behavior of the HMs understudy is concerned, based on $I_{g e o}$, it could reveal that the playground dust, dormitory dust, school gate dust and canteen dust samples in universities and colleges were practically uncontaminated to moderately contaminated for $\mathrm{Cr}, \mathrm{Ni}$, As and $\mathrm{Zn}$, practically uncontaminated to heavily contaminated for $\mathrm{Cu}$ and $\mathrm{Pb}$, and heavily to extremely contaminated for $\mathrm{Cd}$. The highest $\mathrm{I}_{\text {geo }}$ value for $\mathrm{Cd}$ (5.99) was shown in playground dust.

According to the $\mathrm{I}_{\text {geo }}$ values, only canteen areas were threatened by all the HMs. In general, cooking fumes may be the main reason for these HMs (Sun et al., 2017). Li et al. (2017) had already revealed the direct emission of food, cooking oil, ingredients, and fuel in the cooking process in 
Chinese kitchens would increase the content of $\mathrm{HMs}$, such as $\mathrm{Pb}, \mathrm{Zn}$, $\mathrm{As}, \mathrm{Fe}, \mathrm{Cu}$, and $\mathrm{Cr}$. Additionally, unqualified cookstoves and other cooking utensils would also release heavy metals at high temperatures (Zhang et al., 2017). Indicating, HMs would easily accumulate in the dust around the canteen. Except for the highest $\mathrm{I}_{\text {geo }}$ value for $\mathrm{Cd}$ (5.99) in playground dust, the mean $\mathrm{I}_{\text {geo }}$ values for HMs were lower in playground dust and school gate dust than that in dormitory dust and canteen dust. As the playground and school gate area are relatively spacious areas. The dust in spacious areas would easily effect by local atmospheric flow and hardly accumulate for a long time (Kolakkandi et al., 2020). However, the dormitory and canteen areas are always surrounded by buildings, which would benefit HMs accumulation (Adimalla et al., 2020).

\subsection{Source apportionment of HMs in campus dust}

Source identification of HMs is critical for pollution prevention and human health protection (Li et al., 2020). In general, significant correlations between pairs of HMs always suggest a common or combined origin, whereas weak correlations indicate different origins (Yang et al., 2020).

For the universities in Zone A, the Kaiser - Meyer - Olkin index was 0.739 and the result of Bartlett's sphericity test was significant at $\mathrm{p}<0.001$. Revealing, the HMs concentrations in Zone A was suitable for PCA (Liu et al., 2020a). The loading plot of PCA was shown in Fig. 4. The results demonstrate that there are three eigenvalues higher than 1.00, and these three factors explain $71.8 \%$ of the total variance. 


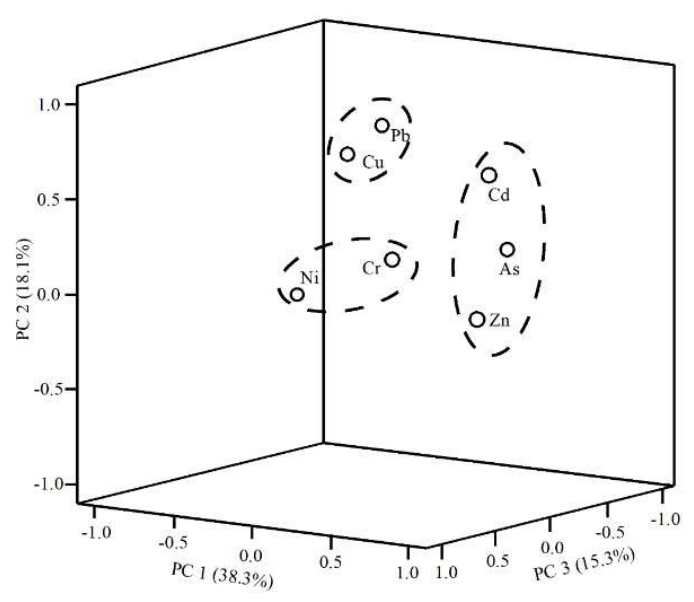

Fig. 4. PCA results of HMs from campus dust in Zone $A$ in the three-dimensional space: plot of loading of the first three principal components. concentration of Cd was significantly higher than the local background value. Many studies (Bhuiyan et al., 2021; Zhang et al., 2015) had already revealed Cd may relatively abundant in the crust rocks of the Yangtze River basin and Hanjiang River basin, indicating that Cd probably originated from natural geochemical processes such as weathering. Additionally, universities would like a small community, people would use fossil fuel for cooking every day. Indicating, fossil fuel combustion would also the probable source for $\mathrm{Cd}$ (Bi et al., 2020). The concentration of $\mathrm{Zn}$ was relatively lower than the local background value. While the concentration of As was slightly higher than the local background value. Indicating, they may source from natural geochemical processes. Additionally, Kolakkandi et al. (2020) also proved As and Zn may also source from fossil fuel combustion. Indicating, the sources of As, $\mathrm{Zn}$, and $\mathrm{Cd}$ had been preliminarily identified to be a mixture of anthropogenic sources, such as fossil fuel combustion and natural geochemical processes such as weathering. In the loading plot (Fig. 
practically uncontaminated to be heavily contaminated for $\mathrm{Cu}$ and $\mathrm{Pb}$. Revealing, they would source from many anthropogenic activities, such as heavy traffic, fossil fuel combustion, and industrial exhausting (Zhang et al., 2012). However, in Wuhan, the universities would more like isolated communities. Teachers and students learning, eating, and living here. Especially, in Zone A, which is the downtown area without industrial activities, the $\mathrm{Cu}$ and $\mathrm{Pb}$ in campus dust would more likely source from cooking. In Chinese kitchens, the use of cooking oil, ingredients, and fuel would emission $\mathrm{Pb}$ and $\mathrm{Cu}$ ( $\mathrm{Li}$ et al., 2015). And the unqualified cook stoves and other cooking utensils would also release $\mathrm{Pb}$ and $\mathrm{Cu}$ at high temperatures (Zhang et al., 2017). Moreover, previous researches also revealed, the accumulation of $\mathrm{Cu}$ and $\mathrm{Pb}$ would commonly release through traffic sources, such as wearing of the vehicular materials and using leaded gasoline (Zhang et al., 2012). Therefore, in some universities with a relatively small campus in Zone A, traffic problems would also affect by anthropogenic activity. Indicating, the sources of As, $\mathrm{Zn}$, and $\mathrm{Cd}$ had been preliminarily identified to be anthropogenic sources, such as cooking and traffic transportation. PC3 accounted for $15.3 \%$ of the total variance and was dominated by $\mathrm{Ni}$ and $\mathrm{Cr}$. The concentration of these two HMs was lower than their soil background values. We observed no obvious geo-accumulation of $\mathrm{Ni}$ and $\mathrm{Cr}$ for most campus dust from Zone A. Therefore, PC3 would likely reflect the contributions of the natural soil weathering.

However, for the universities in Zone B, the Kaiser - Meyer - Olkin index was 0.372 and the result of Bartlett's sphericity test was significant at $\mathrm{p}>0.001$. Indicating, the HMs concentrations in Zone B were suitable for PCA (Liu et al., 2020a). Moreover, Table S7 also revealed the HMs from campus dust showed no significant correlation with each other in Zone B. Zone B is the economic development area with lots of construction projects and industrial parks in Wuhan. HMs in this area 
would from multiple sources. Indicating, the source of HMs from campus dust in Zone B would mainly infect affect by local development, such as industrial activities, heavy traffic, local construction, etc.

\subsection{Potential health risk assessment of heavy metals in campus}

The non-carcinogenic health risks posed by HMs in campus dust for different intake pathways were shown in Table S8. The non-carcinogenic health risk posed by different HMs in campus dust and for the different exposure pathways varies significantly. Generally speaking, among the three routes of exposure, the HQ value of the ingestion pathway was the highest. Similarly, results are also revealed from surface dust and street dust (Tang et al., 2017). Considering the lower body weight than adults, children are believed to be of higher intake of HMs (Zhang et al., 2020). Additionally, health risks through ingestion are greater for children also due to their hand-to-mouth activity (Liu et al., 2020b; Zhang et al., 2020). Their nervous system is still developing and prone to high rates of HMs diffusion (Cui et al., 2020).

For all the people, the health risks were ranked $\mathrm{As}>\mathrm{Pb}>\mathrm{Cr}>\mathrm{Cd}>\mathrm{Cu}>\mathrm{Ni}>\mathrm{Zn}$, based on the HQ value. Additionally, the HQ values for single heavy metal did not exceed the USEPA safe threshold (Wei et al., 2017). Indicating, for teachers and students, single heavy metal would not cause significant non-carcinogenic health risks on campus in Wuhan. However, for children, the HI values of HMs in campus dust from HB-U, WH-U, ZE-SC, WT-U, HT-U, CM-U, CG-U, HZ-U, WHT-U, HE-U, ZE-NC, and WCT-U were 1.39, 1.40, 1.38, 1.25, 1.55, 1.89, 1.37, 1.26, 1.32, 1.50, 1.74, and 1.52, respectively. Indicating, multiple HMs from campus dust from these universities above would cause harm to the physical health of children, and that measures should be taken to mitigate the risks.

Fig. S1 showed for all the people, the HI values of different areas campus dust were ranked 
canteen $>$ dormitory $>$ playground $>$ school gate. For children, the HI values for HMs in these places were all over 1.00. Most children living in university would be the teacher's son and daughter. They would barely go to the dormitory, which is the living place for undergraduate and graduate students. Indicating, the children would more likely to exposure health risks, when eating in the canteen, playing on the playground, or walking around the school gate. Moreover, Fig. S1 also suggested that HMs in campus dust will not damage the physical health of teacher, undergraduate, or graduate students.

Additionally, the carcinogenic risks posed by $\mathrm{Pb}, \mathrm{Cd}, \mathrm{Ni}, \mathrm{As}$, and $\mathrm{Cr}$ in campus dust was showed in Table S9. Based on the findings, the ILCR values of students and teachers in the study area were higher than that of children. Indicating, the relatively high respiration rate would increase the carcinogenic risks for students and teachers (Wahab et al., 2020). However, the carcinogenic risks posed by HMs in campus dust were lower than $10^{-6}$. Indicating, it was significantly lower than the carcinogenic risk level (Adimalla et al., 2020). Therefore, the respiratory intake of HMs does not pose a carcinogenic risk and will not damage human physical health on the campus.

\section{Conclusions}

Our study demonstrated that the average concentrations of HMs in campus dust from universities or colleges in Wuhan ranked $\mathrm{Pb}>\mathrm{Cu}>\mathrm{Cr}>\mathrm{Zn}>\mathrm{Ni}>\mathrm{As}>\mathrm{Cd}$. The contamination level of $\mathrm{Cd}$ was the highest of the seven $\mathrm{HMs}$, followed by $\mathrm{Pb}$ and $\mathrm{Cu}$. And $\mathrm{I}_{\text {geo }}$ values also showed uncontaminated to slightly contaminated with campus dust by As and Zn, while uncontaminated by $\mathrm{Ni}$ and $\mathrm{Cr}$. The distribution of $\mathrm{I}_{\text {geo }}$ values in all universities revealed the accumulation of HMs in campus dust would be influenced by local meteorological conditions. According to the $I_{\text {geo }}$ values, only canteen areas were threatened by all the HMs. The HMs would more likely to accumulate in dormitory dust and 
canteen dust, as the dormitory and canteen areas were always surrounded by buildings. In Zone A, according to the results of PCA, Zn, As, and Cd had been preliminarily identified to be a mixture of anthropogenic sources, such as fossil fuel combustion and natural geochemical processes such as weathering. $\mathrm{Cu}$ and $\mathrm{Pb}$ would source from anthropogenic activities, such as cooking and traffic transportation. While $\mathrm{Ni}$ and $\mathrm{Cr}$ would likely reflect the contributions of the natural soil weathering. However, HMs from campus dust showed no significant correlation with each other in Zone B. Indicating, the source of HMs from campus dust in Zone B would mainly infect affect by the local development, such as industrial activities, heavy traffic, local construction, etc. No significant non-carcinogenic health risks were found to students and teachers by campus dust. However, multiple HMs from campus dust would cause harm to the physical health of children. They would more likely to exposure health risks when eating in the canteen, playing on the playground, or walking around the school gate, especially around the canteen. While the ILCR values revealed respiratory intake of HMs does not pose a carcinogenic risk and will not damage human physical health on campus. However, the accumulation process of HMs in different functional areas in universities would still need to be solved in further research.

\section{Acknowledgements}

We gratefully acknowledge the financial support of the Young Talents Project of Science and Technology Research Program of Hubei Education Department (Q20204503), The National Key Research and Development Program of China (2017YFC0212602), The Scientific and Technological Innovation Team of the Outstanding Young and Mid-age in college of Hubei Province (T201729). Foundation of Talent Introduction Project of Hubei Polytechnic University (18xjz10R), and the Open Foundation of Hubei Key Laboratory of Mine Environmental Pollution Control and Remediation 


\section{Declarations}

\section{Funding}

This work was supported by 1. The Young Talents Project of Science and Technology Research

Program of Hubei Education Department (Q20204503). 2. The National Key Research and

Development Program of China (2017YFC0212602), The Scientific and Technological Innovation

Team of the Outstanding Young and Mid-age in college of Hubei Province (T201729). 3. Foundation

of Talent Introduction Project of Hubei Polytechnic University (18xjz10R). 4. The Open Foundation

\section{Conflicts of interest/Competing interests} that could have appeared to influence the work reported in this paper.

\section{Availability of data and material} supplementary information files].

\section{Code availability}

\section{Authors' contributions}

We would like to introduce the individual author contributions as follows: Conceptualization:

478 [Shan Liu], [Jiaquan Zhang], Data Curation: [Xihao Zhang], [Jun Xu], Formal analysis: [Shan Liu], 
Resources: [Jianlin Guo], [Xinli Xing], Supervision:[ Junji Cao], Writing - original draft: [Shan Liu], Writing - review \& editing: [Changlin Zhan].

\section{Ethics approval}

$$
\text { Not applicable }
$$

\section{Consent to participate}

All authors read and approved the final manuscript.

\section{Consent for publication}

All authors read and approved for publication.

\section{References}

Adimalla, N., Chen, J., Qian, H. 2020. Spatial characteristics of heavy metal contamination and potential human health risk assessment of urban soils: A case study from an urban region of South India. Ecotoxicology and Environmental Safety. 194, 110406.

Bhuiyan, M. A. H., Karmaker, S. C., Bodrud-Doza, M., Rakib, M. A., Saha, B. B. 2021. Enrichment, sources and ecological risk mapping of heavy metals in agricultural soils of dhaka district employing SOM, PMF and GIS methods. Chemosphere. 128339.

Bi, C., Zhou, Y., Chen, Z., Jia, J., Bao, X. 2018. Heavy metals and lead isotopes in soils, road dust and leafy vegetables and health risks via vegetable consumption in the industrial areas of Shanghai, China. Science of The Total Environment. 619-620, 1349-1357.

Bi, X., Zhang, M., Wu, Y., Fu, Z., Sun, G., Fu, Z., Sun, G., Shang, L., Li, Z., Wang, P. 2020. Distribution patterns and sources of heavy metals in soils from an industry undeveloped city in Southern China. Ecotoxicology and Environmental Safety. 111115.

Bourliva, A., Christophoridis, C., Papadopoulou, L., Giouri, K., Papadopoulos, A., Mitsika, E., 
Fytianos, K., 2017. Characterization, heavy metal content and health risk assessment of urban road dusts from the historic center of the city of Thessaloniki, Greece. Environmental Geochemistry and Health. 39, 611-634.

Cao, Z., Yang, Y., Lu, J., Zhang, C., 2011. Atmospheric particle characterization, distribution, and deposition in Xi'an, Shaanxi Province, Central China. Environmental Pollution. 159, 577-584.

Chen, H., Lu, X., Li, L. Y., Gao, T., Chang, Y. 2014. Metal contamination in campus dust of Xi'an, China: A study based on multivariate statistics and spatial distribution. Science of the Total 
Eziz, M., Mohammad, A., Mamut, A., Hini, G. 2018. A human health risk assessment of heavy metals in agricultural soils of Yanqi Basin, Silk Road Economic Belt, China. Human \& Ecological Risk Assessment An International Journal. 24(5), 1-15.

Ferreira-Baptista, L., De Miguel, E. 2005. Geochemistry and risk assessment of street dust in Luanda, Angola: a tropical urban environment. Atmospheric Environment. 39(25), 4501-4512.

Förstner, U., Ahlf,W., Calmano, W., Kersten, M., 1990. In: Dietrich, Heling (Ed.), Sediment Criteria Development-Contributions From Environmental Geochemistry to Water Quality Management.

Gao, P., Liu, S., Ye, W., Lin, N., Meng, P., Feng, Y., Zhang, Z., Cui, F., Lu, B., Xing, B. 2015. Assessment on the occupational exposure of urban public bus drivers to bioaccessible trace metals through resuspended fraction of settled bus dust. Science of The Total Environment. 508, $37-45$.

Hu, X., Zhang, Y., Luo, J., Wang, T. J., Lian, H. Z., Ding, Z. H.,2011.Bioaccessibility and health risk of arsenic, mercury and other metals in urban street dusts from a mega city, Nanjing, China. Environmental Pollution. 159, 1215-1221.

Kaiser, H.F., 1960. The application of electronic computers to factor analysis. Educational and Psychological Measurement. 20, 141-151.

Kolakkandi, V., Sharma, B., Rana, A., Dey, S., Rawat, P., Sarkar, S. 2020. Spatially resolved distribution, sources and health risks of heavy metals in size-fractionated road dust from 57 sites across megacity Kolkata, India. Science of the Total Environment. 705, 135805.

Kusin, F. M., Azani, N. N. M., Hasan, S. N. M. S., Sulong, N.A. 2018. Distribution of heavy metals and metalloid in surface sediments of heavily-mined area for bauxite ore in Pengerang, Malaysia and associated risk assessment. Catena 165, 454-464. 
Li, H. H., Chen, L. J., Yu, L., Guo, Z. B., Shan, C. Q., Lin, J. Q., Gu, Y. G., Yang, Z. B., Yang, Y. X., Shao, J. R., Zhu, X. M., Cheng, Z. 2017. Pollution characteristics and risk assessment of human exposure to oral bioaccessibility of heavy metals via urban street dusts from different functional areas in Chengdu, China. Science of the Total Environment. 586,1076-1084.

Li, Y., Chen, H., Teng, Y. 2020. Source apportionment and source-oriented risk assessment of heavy metals in the sediments of an urban river-lake system. Science of The Total Environment. 140310.

Liu, P., Wu, Z., Luo, X., Wen, M., Huang, L., Chen, B., Zheng, C., Zhu, C., Liang, R. 2020a. Analysis of Heavy Metals in Acidic Farmland of the Karst Region in Southern China-A Case Study of Quanzhou County. Applied Geochemistry. 104764.

Liu, S., Pan, G., Zhang, Y., Xu, J., Ma, R., Shen, Z., Dong, S. 2019. Risk assessment of soil heavy metals associated with land use variations in the riparian zones of a typical urban river gradient. Ecotoxicology \& Environmental Safety, 181, 435-444.

Liu, S., Zhan, C., Zhang, J., Liu, H., Xiao, Y., Zhang, L., Guo, J., Liu, X., Xing, X., Cao, J. 2020 b. Polycyclic aromatic hydrocarbons in railway stations dust of the mega traffic hub city, central China: Human health risk and relationship with black carbon. Ecotoxicology and Environmental Safety. 205, 111155.

Lu, X., Zhang, X., Li, L.Y., Chen, H. 2014. Assessment of metals pollution and health risk in dust from nursery schools in Xi'an, China. Environmental Research. 128, 27-34.

Lyu, Y., Liu, L., Guo, L., Yang, Y., Qu, Z., Hu, X., Zhang, G. Deposited atmospheric dust as influenced by anthropogenic emissions in northern China. Environmental Monitoring and Assessment. 189,390. 
Ma, Z. D., Zhang, D. C., Bi, X. Y., Liu, G. Q., Ren, L. M., Quan, H. L. (2005). Origin of cadmium high-value zones along the Yangtze River and Hanjiang River in Wuhan, Hubei, China (in Chinese). Geological Bulletin of China, 24(8), 740-743.

Men, C., Liu, R., Xu, F., Wang, Q., Guo, L., Shen, Z. 2018. Pollution characteristics, risk assessment, and source apportionment of heavy metals in road dust in Beijing, China. Science of the Total Environment. 612, 138-147.

Muller, G. 1969. Index of geo-accumulation in sediments of the Rhine River. Geojournal. 2, 108-118.

Pan, H., Lu, X., Lei, K. 2017. A comprehensive analysis of heavy metals in urban road dust of Xi'an, China: Contamination, source apportionment and spatial distribution. Science of the Total Environment. 609, 1361-1369.

Padoan, E., Romè, C., Ajmone-Marsan, F., 2017. Bioaccessibility and size distribution of metals in road dust and roadside soils along a peri-urban transect. Science of The Total Environment. 601-602, 89-98.

Qadeer, A., Saqib, Z. A., Ajmal, Z., Xing, C., Khalil, S. K., Usman, M., Huang, Y., Bashir, S,. Ahmad, Z., Ahmed, S., Thebo, K, H., Liu M. 2020. Concentrations, pollution indices and health risk assessment of heavy metals in road dust from two urbanized cities of Pakistan: Comparing two sampling methods for heavy metals concentration. Sustainable Cities and Society. 53, 101959.

Rahman, M. S., Khan, M. D. H., Jolly, Y. N., Kabir, J., Akter, S., Salam, A. 2019. Assessing risk to human health for heavy metal contamination through street dust in the Southeast Asian Megacity: Dhaka, Bangladesh. Science of the Total Environment. 660, 1610-1622.

Sahakyan, L., Tepanosyan, G., Maghakyan, N., Kafyan, M., Melkonyan, G., Saghatelyan, A. 2019. Contamination levels and human health risk assessment of mercury in dust and soils of the urban 
environment, Vanadzor, Armenia. Atmospheric Pollution Research. 10, 808-816.

592

Soltani, N., Keshavarzi, B., Moore, F., Tavakol, T., Lahijanzadeh, A. R., Jaafarzadeh, N., Kermani, M. 2015. Ecological and human health hazards of heavy metals and polycyclic aromatic hydrocarbons (PAHs) in road dust of Isfahan metropolis, Iran. Science of the Total Environment.. $505,712-723$.

Sun, J., Shen, Z., Zhang, L., Lei, Y., Gong, X., Zhang, Q., Zhang, T., Xu, H., Cui, S., Wang, Q., Cao, J., Tao, J., Zhang, N., Zhang, R. 2019. Chemical source profiles of urban fugitive dust $\mathrm{PM}_{2.5}$ samples from 21 cities across China. Science of the Total Environment. 649, 1045-1053.

Sun, J., Shen, Z. X., Cao, J. J., Zhang, L. M., Wu, T. T., Zhang, Q., Yin, X. L., Lei, Y. L., Huang, Y., Huang, R.J., Liu, S.X., Han, Y.M., Xu, H.M., Zheng, C.L., Liu, P.P., 2017. Particulate matters emitted from maize straw burning for winter heating in rural areas in Guanzhong Plain, China: current emission and future reduction. Atmospheric Research 184, 66-76.

Świetlik, R., Trojanowska, M., Strzelecka, M., Bocho-Janiszewska, A., 2015. Fractionation and mobility of $\mathrm{Cu}, \mathrm{Fe}, \mathrm{Mn}, \mathrm{Pb}$ and $\mathrm{Zn}$ in the road dust retained on noise barriers along expressway-A potential tool for determining the effects of driving conditions on speciation of emitted particulate metals. Environmental Pollution. 196, 404-413.

Tadesse, A. W., Gereslassie, T., Xu, Q., Tang, X., Wang, J. 2018. Concentrations, distribution, sources and ecological risk assessment of trace elements in soils from Wuhan, Central China. International Journal of Environmental Research and Public Health. 15, 2873.

Tang, Z., Chai, M., Cheng, J., Jin, J., Yang, Y., Nie, Z., Huang, Q., Li, Y. 2017. Contamination and health risks of heavy metals in street dust from a coal-mining city in eastern China. Ecotoxicology and Environmental Safety. 138, 83-91. 
613

614

615

616

617

618

620

621

622

623

624

625

626

628

629

630

631

632

633

634

Trujillo-Gonzalez, J.M., Torres-Mora, M.A., Keesstra, S., Brevik, E.C., Jimenez-Ballesta, R., 2016. Heavy metal accumulation related to population density in road dust samples taken from urban sites under different land uses. Science of The Total Environment. 553, 636-642.

USEPA, 1989. Risk Assessment Guidance for Superfund, Volume 1: Human Health Evaluation Manual (Part A), Interim Final. US Environ Prot Agency, Off Emerg Remedial Response, Washington.

USEPA, 2001. Risk Assessment Guidance for Superfund: Volume III-Part A, Process for Conducting Probabilistic Risk Assessment; EPA540-R-02-002. U.S. Environment Protection Agency, Washington, DC, USA.

USEPA, 2009. Office of Solid Waste Emergency Response, Waste and Cleanup Risk Assessment. Risk Assessment Guidance for Superfund (RAGS), Volume I: Human Health Evaluation Manual (Part E, Supplemental Guidance for Dermal Risk Assessment) Interim.

Wahab, M. I. B. A., Razak, W. M. A. A., Sahani, M., Khan, M. F. 2020. Characteristics and health effect of heavy metals on non-exhaust road dusts in Kuala Lumpur. Science of the Total Environment, 703, 135535.

Wei, B., Yang, L. 2010. A review of heavy metal contaminations in urban soils, urban road dusts and agricultural soils from China. Microchemical Journal. J. 94, 99-107.

Wei, B. G., Jiang, F. Q., Li, X. M., Mu, S. Y. 2009. Spatial distribution and contamination assessment of heavy metals in urban road dusts from Urumqi, NW China. Microchemical Journal, 93(2), $147-152$.

Wei, X., Gao, B., Wang, P., Zhou, H., Lu, J. 2015. Pollution characteristics and health risk assessment of heavy metals in street dusts from different functional areas in Beijing, China. Ecotoxicology 
Yang, Y., Yang, X., He, M., Christakos, G. 2020. Beyond mere pollution source identification: Determination of land covers emitting soil heavy metals by combining PCA/APCS, GeoDetector and GIS analysis. CATENA. 104297.

Zhang, C., Qiao, Q., Appel, E., Huang, B. 2012. Discriminating sources of anthropogenic heavy

Zhang, Z., Anwar, M., Zibibula, S. 2019. Pollution assessment and health risks evaluation of (metalloid) heavy metals in urban street dust of 58 cities in China. Environmental Science \& Pollution Research. 26, 126-140.

Zhao, L., Hu, G., Yan, Y., Yu, R., Cui, J., Wang, X., Yan, Y. 2019. Source apportionment of heavy metals in urban road dust in a continental Bcity of eastern China: Using $\mathrm{Pb}$ and $\mathrm{Sr}$ isotopes combined with multivariate statistical analysis. Atmospheric Environment. 201, 201-211.

Zhao, L., Yan, Y., Yu, R., Hu, G., Cheng, Y., Huang, H. 2020. Source apportionment and health risks of the bioavailable and residual fractions of heavy metals in the park soils in a coastal city of China using a receptor model combined with $\mathrm{Pb}$ isotopes. CATENA. 104736. 


\section{Supplementary Files}

This is a list of supplementary files associated with this preprint. Click to download.

- 5.Appendice.doc 